\title{
La clausura femenina del Hospital de las Cinco Llagas de Sevilla en el Antiguo Régimen
} Women's enclosure in the the Hospital of the Five Wounds in Sevilla in the Ancient Regime

\section{O encerramento feminino do Hospital das Cinco Chagas de Sevilla no Antigo Regime}

\author{
Rivasplata Varillas, Paula Ermila
}

Doctora en Europa, mundo mediterráneo y su difusión Atlántica. Universidad Pablo Olavide de Sevilla.

Cómo citar este artículo en edición digital: Rivasplata Varillas, P.E. (2014) La clausura femenina del Hospital de las Cinco Llagas de Sevilla en el Antiguo Cultura de los Cuidados (Edición digital) 18, 39.

Disponible en: http://dx.doi.org/10.7184/cuid.2014.39.07>

Correo electrónico: rivasplatavarillas@gmail.com.

Recibido: 07/12/2013; Aceptado: 12/03/2014

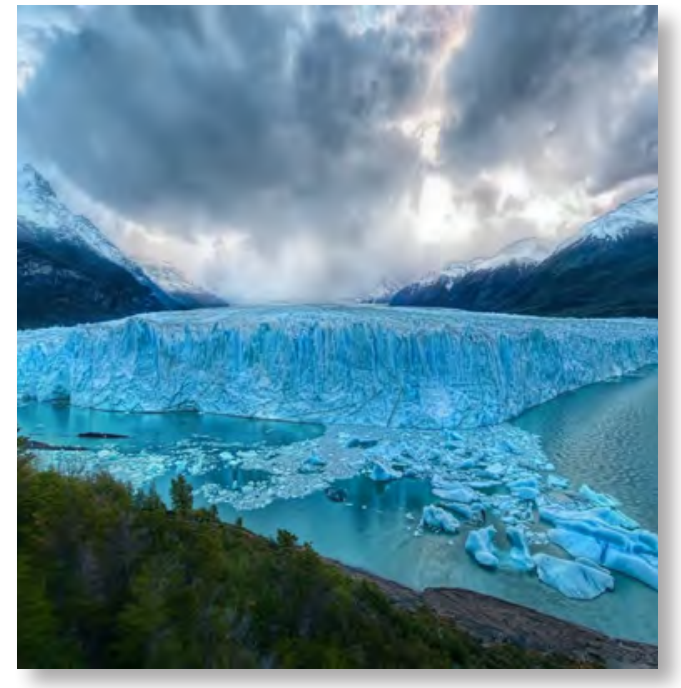

ABSTRACT

The Hospital of the Five Wounds of the city of Seville was found to attend the poor patients and because of the separation of sexes was created a women's infirmary to take care to those women. The "mothers" and "daughters" worked in the called women's enclosure of the Hospital of the Five Wounds during more that three centuries. In this manner, this article studies about the treatment that was given to the feminine infirmaries of this hospital as if they were monasteries, completely separated from the rest of the hospital and with access restricted to the religious and laymen.

Key Words: Seville, The Hospital of the five Wounds, women's enclosure, infirmary, mothers, daughters, Ancient regime.

\section{RESUMO}

O Hospital das Cinco Chagas de Sevilla foi criado para servir os doentes pobres e por causa da separação dos sexos foi formada uma enfermaria feminina para o cuidado destas mulheres. Mães e filhas de dote, trabalhado no fechamento feminino chamado "Hospital de la Sangre" por mais de três séculos. Assim, este artigo analisa o tratamento dado para a fêmea de enfermagem deste hospital, como se fossem mosteiros em reclusão, completamente separada do resto do hospital e com acesso restringido para os machos foram leigos ou religiosos, com um torno e a porta de entrada para a área de fechamento feminino.

Palavras-chave: Sevilha, Hospital de las Cinco Llagas, fêmea de fechamento, enfermeiras, mães, filhas de dote, ancien régime 


\section{RESUMEN}

El Hospital de las Cinco Llagas de Sevilla se creó para atender a enfermas pobres y a causa de la separación de los sexos se formó una enfermería femenina para el cuidado de estas mujeres. Las madres y doncellas de dote trabajaron en la llamada clausura femenina del Hospital de la Sangre durante más de tres siglos. De esta manera, este artículo estudia el tratamiento que se dio a las enfermerías femeninas de este hospital como si fuesen monasterios en reclusión, completamente separadas del resto del hospital y con acceso restringido a los varones fuesen legos o religiosos, con un torno y puerta de entrada al área de clausura femenina.

Palabras Claves: Sevilla, Hospital de las Cinco Llagas, clausura femenina, enfermería, madres, doncellas de dote, Antiguo Régimen.

\section{INTRODUCCIÓN}

Aunque la génesis y el desarrollo del trabajo femenino en los hospitales se abordan desde la Alta Edad Media hasta la actualidad, el núcleo central del presente trabajo comprende los siglos XVI a comienzos del XIX, lo que historiográficamente llamamos como Antiguo Régimen. Teniendo en cuenta lo precedente, el presente estudio se ha llevado a cabo con el objetivo fundamental de conocer el trabajo femenino desempeñado en el hospital de las Cinco Llagas de Sevilla, un reducto de reclusión femenino, donde la sociedad permitió el desarrollo a plenitud del oficio de la "enfermería" a la mujer dentro del contexto de la sociedad patriarcal del Antiguo Régimen.

Es muy probable que la mujer asistiese en la Edad Medieval tanto a hombres como mujeres, pero paulatinamente se le fue restringiendo sólo a la sala de mujeres enfermas, así lo vemos instituido en las constituciones de los principales hospitales españoles del siglo XIV. La labor asistencial de la mujer fue más aceptada y abierta en la Alta Edad Media ya que en la Baja Edad Media la imagen y la consideración social de al menos la sanadora empeoró notablemente, en un proceso gradual de degradación que coincidió con el desarrollo institucional del ejercicio de la medicina y con el resurgimiento de tradiciones intelectuales misóginas al calor de instituciones como la universidad (Cabré, 2006) (Dangler, 2001) (Salmón y Cabré, 1998).

En el Antiguo Régimen, las evidencias indican que la mayoría de las mujeres vivían bajo una economía de subsistencia, en donde el trabajo intenso en distintas actividades era su forma cotidiana de vida, y que había oportunidades y realidades más allá de las opciones más conocidas: matrimonio o convento. Así, las instituciones hospitalarias ofrecieron a las mujeres diversos tipos de trabajos, dando la oportunidad a las jóvenes púberes no sólo de trabajar para subsistir, sino de aprender un oficio en el que podían ascender y cumplir las demandas que la sociedad como mujeres les imponía pudiendo obtener una dote a modo de recompensa al dejar de prestar sus servicios en el periodo de tiempo determinado para ello. Pero los hospitales no sólo fueron una oportunidad para las jóvenes solteras en busca de un aprendizaje y una dote, sino que también fueron una opción de vida para las viudas y para las casadas cuyos esposos estaban ausentes principalmente en Indias, en el caso sevillano. Su trabajo en el hospital les permitía acceder a un salario, al reconocimiento social y a veces a la jubilación, aunque todo ello fuera asociado a la reclusión.

El uso de la mano de obra femenina permitía a los hospitales llevar a cabo su labor de 
asistencia y cuidados sin incurrir en los costes que el personal masculino, normalmente no recluido habría supuesto y aprovecharse de los saberes y roles tradicionales de las mujeres, los domésticos, no considerados cualificados y por tanto, a un coste relativo a su aparente falta de cualificación. El cuidado de enfermos era una actividad muy demandada entre las mujeres por lo que desde muy temprano históricamente, la mujer -núbil, casada, viudaencontró un lugar de trabajo exclusivamente femenino como el hospital, concretamente el área femenina, donde confluyó en ella una variable única como fue la reclusión femenina, que les permitió desarrollar plenamente sus labores cuidadoras, regidas por sus propias pautas de vivencia y conducta que apenas se vislumbra en las constituciones o los reglamentos hospitalarios y masculinos.

El carácter exclusivamente caritativo de los cuidados de enfermería impidió la transmisión sistemática y organizada de los conocimientos de los cuidados, imposibilitando la creación de un corpus específico de conocimientos. Así, el concepto de ayuda que impregnaba la praxis enfermera, bloqueo durante mucho tiempo la sistematización de los conocimientos disciplinares, siendo recién en el siglo XVII cuando se publica La Instrucción de Enfermeros en Madrid (Fernández, 1625). Además, la humildad característica de una enfermera o enfermero impedía la divulgación de sus quehaceres, pues estaban destinados a Jesús a través de la ayuda del otro. Pero, si el enfermero varón escribió su oficio, la mujer enfermera nunca lo hizo, pues se consideraba la asistencia y el cuidado al otro funciones naturales e innatas en la condición del ser femenino, en donde, según tradición europea, valen más los hechos que las palabras.

La enfermería femenina del ámbito religioso desde su perspectiva caritativa, no podía permitirse la constitución de un gremio, por poseer una dimensión exclusivamente espiritual, sin connotaciones materiales, pero si existía un proceso de aprendizaje y mejoramiento de la calidad de la atención del enfermo, pero transmitida de forma oral y por el ejemplo. La enfermería femenina no se limitaba al hogar, se extendía a la comunidad, ya fuese hospitales, casas de los pobres, cárceles e incluso calles donde caían exánimes los enfermos.

\section{ESTADO DE LA CUESTIÓN}

Para la realización de este trabajo se consultaron diferentes fuentes bibliográficas, libros y revistas, sobre el trabajo femenino hospitalario. Los libros consultados abarcaron desde estudios de beguinas y beatas hasta enfermería femenina en sí. Así tenemos, Rivasplata Varilllas, P. E. (2012, 2011), Vinyoles Vidal, T. (2011), Martínez Martin, M.L. y E. Chamorro Rebollo (2011), López Beltrán, M. T. (2010), Rey Castelao, O. (2010), Rivera, M. M. (2006), Gil Ambrona, A. (1996), Eseveri Chavarri, C. (1995), García Arancón, R. (1988) y Colin J. (1989). En cuanto a las revistas y congresos se han consultado Teresa Morales, C. y García Berrocal, F.J. (2013), Blasco Solana, M. (1996), Tey i Freixa, R. (1996), Hernández Martin, F. y M. E. Pinar García (1996), Gil Sacaluga, R. (1996), Gonzales Jiménez, M. (1996), Fargues Garcia, I. (1996) y Jiménez Rodríguez, I. (1996).

La historiadora Margarita Birriel Salcedo en su artículo La experiencia silenciada. Las mujeres en la historia moderna de Andalucía (1994) nos informa sobre el Primer Encuentro Interdisciplinar de Estudios de la Mujer en Granada (1988) y de los avances en cuanto al estudio de la mujer andaluza hasta entonces. Así se indicó que la mujer como ama de cría, enfermera, matrona, criada, lavandera en los 
hospitales, hospicios, beaterios y otros centros asistenciales en la Edad Media y en la Moderna había sido un tema de investigación casi ignorado o muy poco estudiado. La historiadora Monserrat Cabré (2006) enfatiza que a pesar de la contundencia de testimonios escritos y gráficos sobre la participación femenina en la salud y el cuidado en las épocas medieval y moderna ha sido ignorada su presencia, e indica, acertadamente, que cuando algo se ignora, es difícil documentar y estudiar. Para la elaboración de este articulo también se ha utilizado los siguientes libros La Historia de las mujeres: Una Revisión Historiográfica (Valdivieso Val y otros, 2004) y La historia de las mujeres: perspectivas actuales (Borderías, 2009). De esta manera, la historia de las mujeres está abierta a la innovación, al permanente cuestionamiento teórico y a la complejidad para poder dar respuesta a los interrogantes y planteamientos dicotómicos que nos ofrece la realidad.

\section{FUENTES Y MÉTODO}

Este trabajo es fruto de una investigación de tipo archivístico pues se ha trabajado con la información documental proporcionada fundamentalmente por el Archivo de la Diputación Provincial de Sevilla y con otros archivos como el Archivo Histórico Provincial de Sevilla, Archivo Arzobispal de Sevilla, Archivo de Indias y la Biblioteca Colombina.

En el Archivo de la Diputación Provincial de Sevilla se han consultado los libros y legajos del Hospital de las Cinco Llagas de Sevilla: los libros de juntas patronales, libros de recibo y gasto, libros de mayordomía, libros de cuentas, libros de nombramiento de dotes, libros de salarios, libros de entradas y salidas de enfermos y libros de almonedas. También se recurrió al libro anual de capellanías, misas, memorias, testamentos y las cuatro constituciones o re- glamentos -1503, 1603, 1624 y 1734- que generó este hospital durante el Antiguo Régimen.

Las diversas constituciones surgidas durante la historia del hospital en el Antiguo Régimen sirvieron para esquematizar el trabajo de investigación, permitiéndome encuadrarlo y delimitarlo en forma preliminar. Una vez hecho esto, se tuvo que contrastar con la información recogida en los libros capitulares, salarios y otras fuentes documentales. Al final descubrimos que las constituciones se encuentran desfasadas en el tiempo y que se van quedando obsoletas por lo que una nueva constitución sólo reactualiza lo que ya en la práctica se estaba realizando como síntesis. Así, una constitución mientras más alejada este del año a analizar menos se atendría a ella. El problema de los reglamentos es que muchos historiadores lo han considerado suficiente para el conocimiento del hospital. Lo que dista mucho de ser cierto, y la investigación requiere ser abordada con otros documentos como los libros capitulares. De esta manera, gracias a la documentación guardada en los diferentes archivos consultados se ha podido conocer $y$ estudiar estas desconocidas realidades femeninas, las actividades que las mujeres desarrollaron en estos centros y la organización interna y jerárquica de la institución hospitalaria, entre otras cosas.

La información archivística obtenida se ha complementado con las fuentes bibliográficas secundarias consultadas para indagar el trabajo realizado por mujeres en diferentes hospitales españoles y europeos de la época para contrastar el trabajo realizado por las enfermeras del hospital de las Cinco Llagas de Sevilla. Posteriormente se ha procedido a realizar el análisis hermenéutico de toda la información recolectada, dando como resultado una investigación nueva, fresca e descubridora, así como 
descriptica y analítica, de la realidad de la mujer que trabajó en uno de los más importantes hospitales del Antiguo Régimen hispano.

\section{DESARROLLO DEL TEMA}

\section{La casa de comunidad y clausura de mujeres del Hospital de las Cinco Llagas de Sevilla}

En 1500, el hospital de las Cinco Llagas de Sevilla fue fundado por doña Catalina de Ribera y Mendoza, perteneciente a una de las familias más importantes y acaudaladas de Sevilla, esposa de don Pedro Enríquez de Rivera, Adelantado Mayor de Andalucía (Carmona, 1989). Este hospital estuvo destinado a mujeres pobres enfermas, cuyas dolencias no fuesen incurables ni contagiosas, como bubas, recibiéndose enfermas con enfermedades de calenturas, de cámaras, heridas, postemas, llagas frescas, fracturas y dislocaciones (Rivasplata, 2011). La dotó con un cuantioso patrimonio y obtuvo el permiso, licencia y autoridad del papa Alejandro VI en dos bulas, las de $1500 \mathrm{y}$ 1502. También otorgaron otras bulas Clemente VII en 1524 y Julio III en 1549, por las que este hospital obtuvo el privilegio de la excepción de la jurisdicción ordinaria. Este hospital fue administrado por un patronato cuya presidencia se turnaba entre las tres sedes que la regían: Santa María de las Cuevas, San Jerónimo de Buenavista y San Isidoro del Campo.

Este hospital se autodenominaba a sí misma "casa de comunidad y clausura de mujeres" y era una unidad de producción, de consumo, de socialización, de control social, de prestación de servicios, de protección social, de solución de conflictos internos, de amparo ante contingencias adversas y de transmisión patrimonial testamentaria. Lugar donde coincidía el lugar de residencia con el espacio de trabajo. El hospital tenía por política ayudar a sus trabajadores permanentes como ministros mayo-

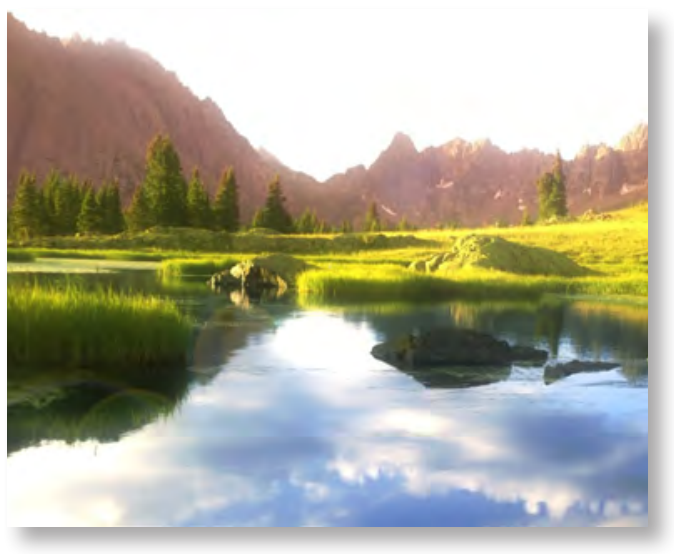

res y menores con las llamadas "ayudas de costa”, también, aseguraba la asistencia durante la vejez y condonaba el tiempo de permanencia en el hospital a los empleados temporales como las doncellas de dote quienes tenían que trabajar tres años consecutivos en el hospital para recibir una dote para matrimonio.

El área femenina del Hospital de la Sangre existió desde su fundación en 1500, ya que estaba destinado al cuidado de mujeres pobres, aunque no de manera exclusiva, pues una bula papal permitió la atención a varones desde 1527, si bien restringida en la práctica a eclesiásticos atendidos por enfermeros. Desde un principio, las enfermas tuvieron un servicio permanente de enfermeras y una atención temporal del físico cirujano que se ocupaba de la salud corporal mientras que los curas, del cuidado del alma.

Consideraban peligroso a la fama y buen nombre de un hospital de jurisdicción directa del Vaticano el contacto cercano entre hombres y mujeres, lo prohibieron, estableciendo un área exclusiva de mujeres, estando prohibido el acceso de hombres a excepción de los necesarios. Desde 1503, denominaron al área femenina "la clausura". De esta manera, este hospital estableció un área femenina a cargo de una matrona, que gobernaba a mujeres libres y esclavas que se dedicaban a la atención 
de las enfermas y al trabajo doméstico. Sin embargo, cambió drásticamente esta situación desde 1559, al trasladarse el hospital a un nuevo establecimiento a extramuros de la ciudad. De esta manera al aumentar el tamaño físico del hospital, ingresaron más enfermas y se incrementaron las obligaciones del personal.

En el área de clausura, se concentraban en su mayoría viudas y solteras, las madres enfermeras, que destinaban sus vidas al cuidado exclusivo de los enfermas, manteniendo un nombre y personalidad jurídica dentro del hospital; las otras mujeres fueron las doncellas de dote, trabajadoras temporales, cuyos destinos estaban orientados al matrimonio. Estas mujeres llevaban una vida disciplinada hacia el perfeccionamiento de trabajos considerados femeninos como enfermeras, asistentas, costureras, lavanderas, cocineras y paneteras.

Desde el siglo XVI, en el Hospital de las Cinco Llagas, se ofrecían a las mujeres oficios remunerados y con posibilidades de promoción interna, siempre y cuando aceptaran vivir en reclusión y respetando los reglamentos de un hospital de carácter eclesiástico. Los priores del hospital valoraban la fidelidad, el respeto a la institución, la continuidad en el puesto de trabajo y la cualificación adquirida, premiándolas con ayudas de costa, jubilación, atención durante la vejez y ofreciendo dotes de matrimonio a las criadas que permanecieran en sus puestos de trabajo por tres años consecutivos. Además, las jóvenes dejadas por sus padres en el hospital para su formación hospitalaria, lo hacían a sabiendas que vivirían en reclusión para así no estar expuestas a los peligros presentes en toda gran ciudad.

La sociedad consideraba prestigioso que una mujer trabajase en un hospital eclesiástico, en donde encontraba un lugar donde poner en práctica su caridad cristiana, aprender un ofi- cio y tener la oportunidad de ascender jerárquicamente, encontrándose casos de doncellas jóvenes pobres que lograron ascender a enfermeras mayores e incluso una llegó a ser madre mayor y obtener la jubilación pagada. Así, se observa que las relaciones de las mujeres con el trabajo no eran distintas a las que tenían los hombres al comprobar estas dos realidades en este hospital, ya que se practicaba en él un proceso jerárquico de promoción interna entre sus trabajadores. En el caso de los eclesiásticos, se empezaba siendo curas, para ascender a mayordomo, secretario notario y finalmente optar por el cargo más elevado que era ser administrador del Hospital de la Sangre. Tenían derecho a jubilación que comprendía una retribución económica mensual y un aposento en el hospital o una cama de incurables en la enfermería de eclesiásticos que tenía el hospital. En periodos de crisis económicas, los eclesiásticos cedían parte de sus salarios para entregárselo a los jubilados con la condición que serian retribuidos de tal forma. A veces el cura más joven recibía un salario reducido, cobrando completo cuando falleciese el jubilado. Prácticas similares se llevaron a cabo en el área femenina sólo con la madre mayor y su sustituta desde fines del siglo XVIII. La madre mayor era elegida por los patrones priores de los tres monasterios sevillanos mencionados, recayendo en alguna hidalga viuda. Aunque a veces se producían ascensos entre las madres enfermeras de las diversas especialidades pudiendo alcanzar cualquiera la máxima jerarquía de madre mayor. El ascenso de hombres y mujeres podía no era lineal, no era un derecho adquirido a través de los años, dependía de la capacidad de trabajo, obediencia y fidelidad demostrada a la institución y si demostraba constancia y eficacia en su trabajo para no generar "atrasos" al hospital. 
El área femenina de este hospital se subdividía en enfermería, cirugía, agonizantes, convalecientes, incurables, ropería, cocina, panadería y portería. Este hospital admitía a jóvenes para ser educadas en el cuidado del prójimo con caridad y piedad, viviendo en el sitio donde estuviesen destinadas a trabajar y se le pagaba un salario y una dote para tomar matrimonio o convento (Rivasplata, 2011). Estas jóvenes trascurrido el tiempo de su estadía -tres años- regresaban a la vida de familia, aunque algunas veces permanecían en el hospital, convirtiéndose en madres enfermeras. Cada madre ejercía de maestra de las doncellas de dote, enseñándole los quehaceres del área asignada. Estas mujeres tenían sus camas en las habitaciones donde laboraban, a excepción de la madre mayor, la cual tenía una habitación independiente al igual que los ministros mayores del hospital.

\section{El personal femenino del Hospital de las Cinco llagas de Sevilla}

\section{a) Las Madres del Hospital de la Sangre}

Específicamente en el cargo de madre mayor se prefería a las hidalgas, letradas y familiares de algún cura o fraile del hospital, preferentemente del administrador. Esto no lo indicaba el reglamento, pero solía suceder. Algunas de las madres mayores eran mujeres de estatus de hidalguía como las madres mayores Aldonza Juana Ponce de León y Fajardo, Ana Gallegos, Constanza Gallegos y Ana de Meneses, pero también, hubo una madre mayor que ingresó al hospital como doncella de dote, y ascendió a ese cargo. Se llamaba María de San Jerónimo.

En cuanto a las madres eran las autoridades superiores de las diferentes secciones del área femenina. Generalmente, estas mujeres eran viudas, solteras, es decir personas solas, sin familia a quien cuidar y dependencias a que atender, para que puntualmente cumplieran con sus tareas en el hospital. A estas mujeres sólo se les exigía que fueran personas de buenas costumbres y cristianas, aunque hubo beatas.

Las funciones de las madres eran enseñar con el ejemplo, así como vigilar y supervisar el trabajo asistencial de las doncellas de dote, rondar la enfermería femenina, seguir la evolución de las enfermas, probar la comida que se ofrecía a las enfermas, comprobar que la enfermería estuviese aseada con camas limpias y bien hechas, dar la medicina a las enfermas, vigilar y controlar el ingreso de personas ajenas al hospital y asegurar el avituallamiento de la enfermería femenina, etc. Las madres enfermeras dependían inmediatamente de la madre mayor y en última instancia del administrador. Vivían recluidas en el hospital, sin libertad para salir, a excepción de algunos permisos otorgados por el administrador. El número de funciones de las madres fluctuó de uno a ocho en el siglo XVI y de diez a doce en el XVIII. Las madres dejaban el cargo que desempeñaban en el hospital por motivos de fallecimiento, jubilación o por decisión propia. Pero es bastante común encontrar que morían ejerciendo el cargo de madre al cual estaban asignadas. Algunos de estos oficios tenían requisitos especiales como saber leer para reconfortar con oraciones impresas, correspondientes a las madres agonizantes o del buen morir.

La madre de la sala de medicina se encargaba de asistir a las enfermas con problemas estomacales, respiratorios, fiebres, etc. No trataban enfermedades contagiosas, sólo en caso de pestes. La madre cirujana se encargaría de ayudar al cirujano con las enfermas heridas, fracturadas, con úlceras y llagas frescas. El puesto de madre portera era un cargo de gran 
responsabilidad porque se encargaba de la entrada y salida de personas, alimentos y bienes del hospital. La madre panetera amasaba y horneaba el pan, además se encontraban entre sus funciones el lavado de la ropa, lo que pasó después a ser función de la madre ropera y sus doncellas, según constitución de 1734. La madre cocinera era muy importante porque se tenía la clara idea que con una adecuada alimentación se podía curar al enfermo, siendo la comida entregada en el hospital copiosísima.

\section{b) Las hijas o doncellas de dote}

Las doncellas de dote aparecieron en 1587 a pedido de una madre mayor. El tiempo de estadía en el hospital era de tres años para poder recibir una dote de 50 ducados para tomar estado de matrimonio. Además, recibían un salario anual, ración de comida diaria, y la posibilidad de conseguir un ajuar en las almonedas o subastas internas o públicas de la ropa de las enfermas fallecidas. Estas jóvenes provenían en un 30\% de la ciudad de Sevilla, un 60\% del área rural cercana a Sevilla y de Córdoba, Huelva, Extremadura y un 10\% de otras partes de la península Ibérica y algunas extranjeras sobre todo portuguesas, milanesas y francesas (Rivasplata, 2011).

Todas las doncellas de dote o "hijas" que ingresaron al hospital a trabajar eran pobres, aunque egresaban de ella con bienes acumulados, sus ajuares, a través de las almonedas. Práctica recurrente en el Antiguo Régimen de compra y venta de objetos usados de fallecidas del hospital.

Las doncellas ejecutaban las tareas que les asignaban las madres de las distintas enfermerías donde trabajaban. Fluctuaron de seis a catorce plazas de doncellas de dote, aunque prevalecieron doce puestos asignados, que eran ocupados a medida que caducaban. Un puesto era ocupado por una nueva doncella cuando egresaba una de ellas, es decir, cuando la doncella cumplía el tiempo para acceder a una dote (tres años), o cuando deseaba, pues podía quedarse trabajando más tiempo que el normado para ganar otra dote o para convertirse en "madre". Pero la mayoría dejaba el cargo al terminar su periodo de estadía.

La información archivística nos informa que las doncellas cumplieron funciones básicas de cuidado, asistencia inmediata y limpieza. Más específicamente se encargaban de confortar con su presencia a las enfermas, bañarlas, alimentarlas, darles las medicinas, unciones y regalos (bizcochos, azúcar, chocolate) indicados por la madre mayor, vestirlas, recoger sus excrementos y orinales, envolverlas en sudarios y velarlas. También, estas jóvenes realizaban la limpieza de las enfermerías, cocinaban y lavaban la ropa. Tareas que cada una asumía según fuese designada como "doncella" de medicina, cirugía, convalecencia, cocina, lavandería y ropería. Las dotes eran financiadas por diferentes patronatos. Entre los cuales destacaron Juana de Gallegos, las hermanas Núñez Pérez, Diego de Yanguas y el mismo hospital.

El área de clausura tenía diferentes secciones, no necesariamente un aprendiz de enfermería se dedicaba al cuidado directo asistencial de la enferma. En el XVI, las doncellas recién ingresadas trabajaban en el lavado y cocina. Las más experimentadas trabajaban en la sala de medicina y cirugía. En el XVII, sólo una de las doncellas del área de enfermas convalecientes trabajaba en dicha sección, la otra se desempeñaba ayudando en el trabajo del lavado de la ropa. El área que más trabajo demandaba era el lavado y cocina, pues este servicio era ofrecido no sólo para las enfermerías masculinas y femeninas sino para todo el hospital. No se requería mucha experiencia sólo voluntad y fuerza. En el XVIII, las doncellas 
permanecían en sus respectivas enfermerías sin rotación, especializándose en el área que les tocó. En cuanto a las doncellas de ropería, que eran cuatro, una de ellas compartiría sus funciones de lavado de ropa con la asistencia a las enfermas convalecientes. Esto trajo, a veces, problemas con ciertas doncellas que pertenecían a la fundación de convalecientes de Diego de Yanguas que a veces eran incorporadas al patronato de las hermanas Núñez o al fondo hospital, como sucedió con Juana Josefa Bermudo en 1713. Esta doncella cumplía dos funciones ropería y convalecientes, creando duplicidad de funciones y trastornos al secretario del hospital que no estaba habituado a doncellas con labores varias, al final se resolvió el asunto, siendo pagada por la fundación hospital. Este problema se generaba porque el trabajo de la ropería era a veces tan excesivo que se requería de más doncellas de lo habitual.

\section{Evolución histórica de las mujeres que traba- jaron en el Hospital de la Sangre}

Según la primera constitución de 1503, la matrona era la mujer designada al cuidado de las enfermas. Se ocupaba de quince enfermas, atendiéndolas según indicación del cirujano y médico. La botica estaba bajo la responsabilidad de la matrona y recibía las medicinas de un boticario externo en 1509. El hospital tendría un boticario interno a partir de 1542 .

En un comienzo, la matrona era una "enfermera", tal como era conocida, que dirigía a las demás mujeres fuesen criadas o esclavas. La madre cocinera apareció más tarde, pues de esta actividad como del lavado se ocupaban las esclavas y criadas. La enfermera ganaba 2.000 mil maravedíes igual que el médico y cirujano, y más que el boticario y barbero. La cocinera ganaba 1.228 maravedíes igual que el despensero. El salario de la matrona enfermera equiparable a los del médico y cirujano sólo se dio a comienzos del siglo XVI, posteriormente aumentaría drásticamente el salario masculino. Así, en un pequeño lapso de tiempo de 29 años, se valoró la labor cuidadora femenina "no académica" tanto como el trabajo sanitario "académico" masculino.

Las primeras mujeres que trabajaron en este hospital serían las enfermeras Catalina Maza y Beatriz y las lavanderas Beatriz y Iohuana. En 1509 estaban las enfermeras Teresa García, Mari Rodríguez, las esclavas Juana de Rivera y Beatriz. En 1512, ya estaban claramente establecidas una enfermera y una cocinera que dirigían a criadas y esclavas. En 1520 a 1529 la enfermera fue Isabel Buena y la cocinera Isabel González. Como se ha mencionado, había esclavas que doña Catalina de Ribera dejó al hospital en forma testamentaria que se destinaron a la cocina y lavado como Juana y Gemna. La primera adoptó la filiación a su ama, llamándose Juana de Ribera que "lava y cuece” en 1512 y de la segunda se perdió el rastro. También se menciona a Beatriz esclava cocinera. A todas estas esclavas se les daba dinero para su vestido y calzado. Además de las raciones de comida diarias (5 maravedíes por cabeza).

De 1500 a 1546, el papel de las mujeres que atendían a las enfermas del hospital fue crucial para el hospital y la matrona figura como personaje principal para el buen funcionamiento del establecimiento, requiriéndose, también, la presencia del clérigo o administrador (asistencia espiritual a las enfermas) y del mayordomo (recaudador de rentas).

El trabajo desempeñado en el área de clausura se fue sectorizando en especialidades a medida que aumentaba la afluencia de enfermas al ir diversificándose el servicio que ofrecía el hospital a la colectividad. Paulati- 
namente surgieron otras "cuidadoras" o madres, ya que se necesitaron de más servidoras responsables de cada área de la clausura para dirigir a las criadas que tenían a su cargo y lograr que las cosas en el hospital estuviesen "bien hechas y con mucha limpieza".

A mediados del siglo XVI, en el área de clausura, las madres que existían fueron la madre mayor conocida en aquel entonces como la matrona o madre de llaves, junto a la madre de sala, ropera y cocinera, esta última de rango inferior. Paulatinamente, se incrementó el número de madres, dirigiendo y realizando diversos trabajos considerados de exclusividad femenina como lavar, cocinar, limpiar y cuidar. También se les instaba a obedecer, consolar y rezar. Además de las madres, fue grande la afluencia de otras mujeres que trabajaron permanente y temporalmente en el hospital desde 1559 cuando se trasladó el hospital de la parroquia de Santa Catalina a su nuevo emplazamiento renacentista en la Macarena. Se trataba de las criadas y posteriormente conocidas como doncellas de dote. En 1572, se menciona a una criada, llamada Catalina Morena quien solicitó una ayuda a su casamiento a los patronos del hospital por haber servido "con mucho cuidado a los pobres en el hospital mucho tiempo desde los tiempos de peste", consistente en una cama que costaba 13 reales (Rivasplata, 2011). Este dato es de suma importancia porque nos indica que aún no se habían establecido las dotes a doncellas en el hospital.

Tomó un siglo 1503 a 1603 perfilar las características intrínsecas del hospital en cuanto a oficios, salarios y tener claramente definida la estructura del hospital, creándose inclusive en 1587 la entrega de dotes para tomar estado de casada entre las doncellas que trabajaban como sirvientas en el hospital. En la segunda constitución de este hospital, la de 1603, son

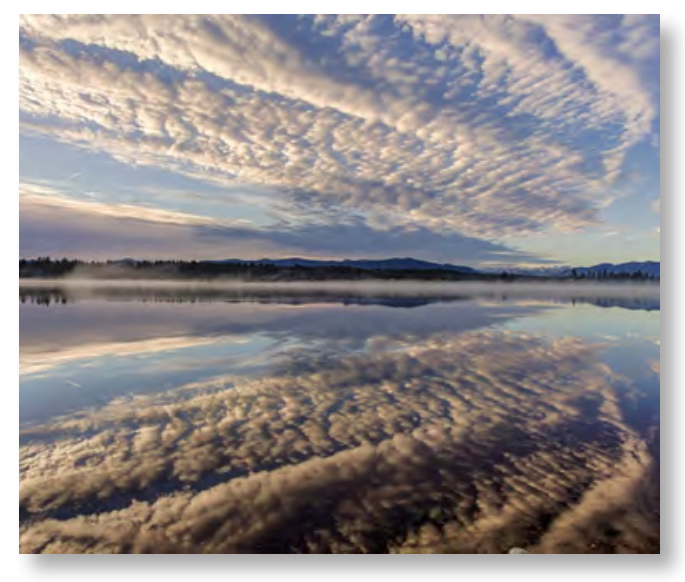

indicadas las labores femeninas: la madre mayor, la madre ropera, enfermera mayor, la madre tornillera, la madre portera, la madre panetera y la madre cocinera, cada una con sus respectivas mozas o doncellas. Así, vemos que el personal femenino se especializó y amplió en forma bastante acelerada en el lapso de un siglo desde 1503, de tal manera que la constitución de 1603 recoge este cambio, adaptándose a la nueva coyuntura, en donde la cantidad de trabajadoras es sorprendentemente mayor en conjunto que en el siglo anterior. La constitución de 1603 nombra por vez primera a las doncellas de dote, pero no especifica más sobre ellas. En 1604 se nombró por junta patronal a la doncella de sala, moza de la madre mayor que no se logró incluir en la constitución de 1603.

A comienzos del siglo XVII, la segunda constitución del hospital de 1606 ya había formalizado una etapa previa de experimentación con el personal femenino hospitalario, determinándose que todas las madres indistintamente su especialidad se les diesen 14 reales de vellón cada mes y que tuviesen un número designado de ayudantas o doncellas dotadas a su cargo y vigilancia.

Por entonces, el área femenina del Hospital de las Cinco Llagas tenía ya establecida su con- 
figuración jerárquica, dividida en una especie de pirámide invertida cuyo vértice estaba regido por la madre mayor, siendo intermedias las madres de las diversas especialidades, seguidas por las doncellas de dote y la base lo constituían las trabajadoras temporales para casos puntuales, las donadas y las esclavas. La división se estableció de la siguiente manera:

1) Administración y control: la madre mayor y su secretaria.

2) Enfermería: las madres enfermera, cirujana, buen morir, incurable y convaleciente.

3) Portería: la madre portera y la madre del tornillo.

4) Cocina, limpieza y lavado de ropa: las madres cocinera, panetera y ropera que se encargaban de hacer las comidas diarias y el pan, limpiar pasillos y habitaciones y lavar la ropa. El cucharón, la escoba, el trapo, la aguja y el hilo serían utensilios propios de estas áreas donde eran muy numerosas las doncellas de dote, las criadas y algunas esclavas.

Poco a poco, la clausura del Hospital de la Sangre se fue especializando y aparecieron además del área de enfermería, el área de cirugía (1571), el área de agonizantes (1618), el área de incurables (1620) y el área de convalecientes (1637). Cada una de estas áreas estaba bajo el control de una madre especialista con la dirección de la madre mayor. Las madres auxiliares ya estaban creadas mucho antes casi a la par de la madre mayor, me refiero a la madre cocinera, ropera, portera y panadera.

Los cargos que desempeñaban las madres, como todos los demás en el hospital, no eran estables para poder ser removidas por los patronos en caso de ineficacia en su labor. Exigían que las madres fuesen cristianas y tu- viesen como características intrínsecas la humildad, la caridad, la templanza, la obediencia y la paciencia para poder cuidar y consolar a las enfermas. Se requería que las madres tuviesen experiencia en la atención a enfermos, así en 1738 se dieron preferencia a las que habían sido "vagantes" o habían prestado servicio temporal (Rivasplata, 2012). Entre las madres había beatas y miembros de alguna orden tercera, las que se comprometían a cumplir con los votos de obediencia, pobreza y castidad, aunque no llegasen a profesar (Gil, 1996). Sólo algunas madres lograban permanecer en sus cargos por las exigencias y los controles a las que estaban sometidas, siendo recompensadas al final de sus vidas con una jubilación que consistía en un pequeño salario y manutención en el hospital hasta su muerte.

La jerarquía era primordial, obediencia al administrador y a la madre mayor. De esta manera, la madre mayor tenía su lugar establecido en la alta jerarquía del hospital en todos los actos públicos, como ministro mayor, estando ubicada después de los curas. El objetivo era guardar el respeto a la jerarquía en la familia del hospital. Esto se hacía "para evitar disturbios y ocasiones de discordias atendiendo a las personas y circunstancias que componen la familia del hospital” (Rivasplata, 2012).

Era primordial el respeto, cumpliendo sus obligaciones sin "meterse unos con otros" $y$ que "unos con los otros se traten con amor y cortesía, y haciendo lo contrario se proveerá del remedio que convenga". Y se advertía que "este hospital, como en otras casas de comunidad, suelen fomentarse algunos disturbios, procedidos de la diversidad de genios, que la componen" (Constitución del Hospital de las Cinco Llagas de 1734). El administrador y los patronos tomaban medidas necesarias para solucionar estos conflictos, siendo los 
responsables directos los ministros bajo cuya jurisdicción se producían. Si se encontraba culpa, les daban hasta tres oportunidades para enmendarlo antes de tomar medidas más drásticas. Por ejemplo, si se producían perdidas en el área de ropería, la responsable sería la madre ropera por no controlarlo como jefa de la sección. Las madres, doncellas y enfermas debían a la madre mayor obediencia, respecto y sumisión. Las madres tomaban las decisiones que consideraban convenientes en sus respectivas áreas de trabajo, preocupándose de las necesidades de los miembros que las componían.

\section{Control al área femenina por los priores}

El área femenina era controlada sucesivas veces al año por las autoridades superiores, es decir los patronos - la Cartuja, San Isidoro del Campo y de Jerónimo de Buenavista- en la Visita General en enero, en la Junta General en mayo y cada dos meses por el patrono de turno. Estas últimas eran conocidas como las Visitas Particulares. Estos controles eran compensados con propinas. Se daba comida en la Visita general y refrescos en las juntas y visitas particulares que se preparaban en el área femenina. El día de la Visita General solía ser pública, permitiendo la entrada de hombres y mujeres, con algunas excepciones, especialmente a fines del siglo XVII. En 1756, se pusieron dos o cuatro soldados en la puerta principal del Hospital, porque después del terremoto de noviembre de 1755 había habido pillaje y optaron por dejar entrar tan sólo a hombres vestidos de militar y a mujeres.

El hospital tenía prohibida la entrada al área femenina de toda persona ajena a él, para lo cual necesitaba permiso especial, salvo los patrones durante la visita anual, el confesor de enfermas, el cura semanero, el médico, el cirujano, el boticario o las personas que por fuerza mayor tuviesen que cumplir con sus respectivos trabajos, acompañados por la madre mayor, quien iba tocando una campanilla para avisar de la presencia de hombres en la clausura y las madres y doncellas se retirasen y guardasen las formas que establecía el Concilio de Trento.

La clausura del hospital tenía que ser respetada por lo que se prohibía la salida de mujeres del recinto y del sanatorio y se hacía extensiva a los curas quienes no podían salir del hospital, a excepción del mayordomo. Tampoco nadie podía pernoctar en la clausura, ni siquiera parientes sin permiso del administrador y con la anuencia de la madre mayor desde 1727. Si obtenían los permisos luego al punto se retiraban, especialmente en las horas de la noche y siesta, en cuyo tiempo se tenían las puertas bien cerradas tanto del gineceo como del hospital. La alimentación, la limpieza, el lavado de la ropa y la curación de las enfermedades tenían que ser satisfechas dentro del hospital para todos los que vivían en el recinto. Todos los ministros mayores y menores, así como las madres tenían derecho a salir tres días al año o más en caso de prescripción médica y con previa licencia del administrador.

El acceso al gineceo por los varones, con sus debidas restricciones, era más recurrente que el caso inverso, pues estaba terminantemente prohibido que la mujer circulara fuera del área femenina del hospital. También, estaban prohibidas las visitas de familiares - esposos, hijos, padres, hermanos - en el área femenina, el acceso se permitía previa licencia del administrador a horas regulares y con acompañamiento. Otro motivo de entrada al hospital era su belleza arquitectónica, que motivaba a los forasteros y naturales de Sevilla solicitar la visita a sus instalaciones, lo cual era posible, previo permiso del administrador, siendo 
guiado por una de las madres más antiguas, aprobado según práctica desde 1680.

\section{CONCLUSIONES}

Los hospitales respondían a las necesidades coyunturales que la sociedad patriarcal de la época había impuesto a las mujeres y que éstas acataban y hacían suyas, También los hospitales proporcionaban trabajos a las mujeres que fuesen propios a su naturaleza como "el cuidado del otro", respondiendo a la percepción social que en el Antiguo Régimen se tenía de lo femenino y lo masculino.

Económicamente, los hospitales fueron subvencionados por generosas limosnas (casas, tierras y otros bienes muebles e inmuebles), siendo el trabajo, desempeñado en ellos, pagado con un estipendio mensual en dinero y alimento diario, ampliando el número de mujeres trabajadoras, y pudiendo el personal auxiliar temporal, es decir doncellas y criadas ser recompensadas al final con una dote.

Uno de los objetivos alcanzados en esta investigación ha sido conocer la vida en reclusión de la mujer trabajadora y sus posibilidades de desarrollo laboral. Ya que las instituciones religiosas cobijaban a la mujer en reclusión y en este contexto les permitían escalar profesionalmente. Aunque, hasta el momento, se ha enfocado la reclusión como un término peyorativo y negativo en el trabajo femenino no remunerado, que las familias se beneficiaron en forma gratuita. Me refiero a la reclusión de las mujeres en los espacios domésticos en las sociedades preindustriales en donde la división del tiempo en periodos de trabajo y de ocio no existió y en donde estaba implícito la dicotomía carga emocional-trabajo. Además, la reclusión no sólo estaba destinada a las monjas, sino a toda mujer laica que se encontrase en condición de orfandad, sin marido. También, la practicaron las instituciones religiosas que acogían mujeres solas de forma temporal, fuesen honestas o "arrepentidas" con la intención de "protegerlas del mundo", "separarlas de los hombres" y "remediarlas".

Pero, en este trabajo se observa que no toda reclusión significó explotación, existieron algunas donde la mujer tuvo mayor libertad de expresión y acción: conventos y hospitales. Estas instituciones fueron controladas y supervisadas por la iglesia, por la sociedad patriarcal, pero con restringida entrada a las mismas. El consentimiento masculino de lugares exclusivos para mujeres permitió el desarrollo en ellos de mundos aparte con sus propias reglas, normas y jerarquización, que si bien no están escritas formalmente, se encuentran diseminadas en toda la documentación primaria. Uno de aquellos mundos apenas estudiado corresponde a la reclusión de mujeres ejerciendo trabajos remunerados en los hospitales durante la Edad Moderna. De esta manera, los hospitales constituyeron lugares refugio de muchas mujeres en donde trabajaron en forma organizada y especializada. Así en la Edad Moderna, la larga tradición del trabajo femenino hospitalario le dio a la mujer cierto poder y seguridad bajo el cobijo de estos establecimientos.

De esta manera, la reclusión femenina hospitalaria jugó un papel esencial en las oportunidades laborales de las mujeres como alternativa al matrimonio, aunque sirvió también para conseguirlo a través de la consecución de una dote. Si la primera conclusión del trabajo tiene que ver con el abanico de posibilidades que se les presentaban a las mujeres, la segunda conclusión deriva de las ventajas que obtenían los hospitales derivados del trabajo femenino. Los hospitales se beneficiaron de los saberes "naturales" femeninos para hacer viables la labor del cuidado fuera de los límites familiares. 
La identificación del trabajo de cuidados con la naturaleza femenina y el hecho de que las mujeres siempre lo hayan realizado de manera gratuita en el seno de las familias habría permitido su desarrollo en el ámbito hospitalario. Viudas y solteras trabajaban preferentemente en el hospital. Las primeras eran llamadas "madres" y las segundas "hijas o doncellas".

Pero, la mayor parte de hospitales tenían mujeres laicas como enfermeras, cuyo único requisito fue ser solteras y buenas cristianas. Estas tampoco dejaron testimonio escrito de su desempeño laboral porque eran mujeres que aprendían y enseñaban haciendo. Estas mujeres encontraron una vida digna y segura dentro de los hospitales, si lograban tener las cualidades de obediencia, disciplina, respeto a las normas internas y gran capacidad de trabajo. Características que no eran fáciles de asumir por mujeres laicas por lo que no es extraño que muchas abandonaran este trabajo al poco tiempo.

\section{BIBLIOGRAFÍA}

- Asociación Española de Investigación histórica de las mujeres (1999) Pautas históricas de sociabilidad femenina, rituales y modelos de representación: Actas del V Coloquio Internacional de la A.E.I. H.M., Universidad de Cádiz.

- Birriel Salcedo, M. (1994) La experiencia silenciada. Las mujeres en la Historia de Andalucía. Andalucía Moderna. En: Actas del II Congreso de Historia de Andalucía (Córdoba, 1991). Publicaciones de la Consejería de Cultura y Medio Ambiente de la Junta de Andalucía y obra social y Cultural Caja Sur, Sevilla.

- Blasco Solana, M. (1996) El hospital real y general de nuestra Sra. de Gracia de Zaragoza, en el siglo XVIXVII. Actividad del personal sanitario. En: I congreso Nacional de Historia de la Enfermería. Libro de ponencias y comunicaciones. Fundación Uriach 1838, Barcelona: 29-31.

- Borderías Mondejar, C. (2009) La historia de las mujeres a las puertas del nuevo milenio: balance y perspectivas. En La historia de las mujeres: perspectivas actuales, Icaria, Barcelona.

- Cabré I Pairet, M. (2006). Como una madre, como una hija: las mujeres y los cuidados de salud en la Baja Edad Media”. En: Historia de las mujeres en España y América Latina de la prehistoria a la Edad Media. Ediciones Cátedra, Madrid: T.1: 637-657.

- Carmona García, J. I. (1989) La reunificación de los hospitales sevillanos. Los Hospitales Reales. Hospitales de Sevilla. Real Academia Sevillana de Buenas Letras. Utrera.

- Colin Jones (1989) The charitable imperative. Hospitals and nursin in Ancien Regime and revolutionary france. Routledge. London and New York.

- Eseveri Chavarri, C. (1995) Historia de la enfermería española e hispanoamericana. Editorial universitas, Madrid.

- Dangler, J. (2001) Mediatin Fictions: Literature, women healers, and the Go- Between in Medieval and Early Modern Iberia. Bucknell University Press, Lewinsburg.

- Fargues García, I. (1996) La enfermería en el hospital de la Santa Creu de Barcelona. Siglos XVI y XVII. En: I congreso Nacional de Historia de la Enfermería. Libro de ponencias y comunicaciones. Fundación Uriach 1838, Barcelona: 133-138.

- Fernández, A. (1625) Instrucción de enfermeros para aplicar los remedios a todo género de enfermedades y acudir a muchos accidentes que sobrevienen en ausencia de los médicos. Imprenta del Reino, Madrid.

- García Arancón, R. (1988) El personal femenino del hostal de la Reina Blanca de Navarra (1425-1426). En: El trabajo de las mujeres en la Edad Media Hispana, Asociación Cultural Al-Mudayna, Madrid: 27-41.

- Gil Ambrona, A. (1996) Entre la oración y el trabajo: las ocupaciones de las otras esposas, siglos XVI- XVII. En: El trabajo de las mujeres: siglos XVI- XX. Universidad Autónoma de Madrid, Madrid: 91-105.

- Gil Sacaluga, R. (1996) La atención sanitaria en Cádiz y provincia durante los siglos XVI y XVII. Cuidados, cuidadores y organización. En: I congreso Nacional de Historia de la Enfermería. Libro de ponencias y comu- 
nicaciones. Fundación Uriach 1838, Barcelona: 63-68.

- Gómez García, M. (1996) Trabajo y actividades de las religiosas en los conventos malagueños (s. XVIII). En: El trabajo de las mujeres: siglos XVI- XX. Universidad Autónoma de Madrid, Madrid: 107-116.

- Gonzales Jiménez, M. (1996) Hospitales en Sevilla durante los siglos XIII-XVI. Historia y documentación. En: I congreso Nacional de Historia de la Enfermería. Libro de ponencias y comunicaciones. Fundación Uriach 1838, Barcelona: 83-91.

- Hernández Conesa, J.N. (1995) Historia de la enfermería. Un análisis histórico de la historia de la enfermería. Mc. Graw Hill - Interamericana, Madrid.

- Hernández Martín, F. (1996) Historia de la enfermería en España: Desde la antigüedad hasta nuestros días. Síntesis: Madrid.

- Hernández Martin, F. y M. E. Pinar García (1996) La enfermería en los hospitales madrileños del siglo XVI. Características generales del hospital en la Edad Moderna. En: I congreso Nacional de Historia de la Enfermería. Libro de ponencias y comunicaciones. Fundación Uriach, Barcelona, 1838: 43-50

- Jiménez Rodríguez, I. (1996) La enfermería toledana del siglo XVI a través de los reglamentos hospitalarios. En: I congreso Nacional de Historia de la Enfermería. Libro de ponencias y comunicaciones. Fundación Uriach 1838, Barcelona: 140-145.

- López Beltrán, M. T. (2010) El trabajo de las mujeres en el mundo urbano medieval. En: Mélanges de la casa de Velázquez. Nouvelle serie. El trabajo de las mujeres en España (desde la antigüedad al siglo XX). Tomo 40-2, Casa Velázquez, Madrid: 39-57.

- Martínez Martin, M.L. y Chamorro Rebollo E. (2011). Historia de la enfermería. Evolución histórica del cuidado enfermero. Elsevier, Barcelona: 2011.

- Rey Castelao, O. (2010) Trabajando a cubierto. Las empleadas institucionales a fines del antiguo régimen. En: Melanges de la casa de Velázquez. Nouvelle serie. El trabajo de las mujeres en España (desde la antigüedad al siglo XX). Casa Velázquez, Madrid, Tomo 40-2: 73-93 - Rivasplata Varilllas, P. E. (2011) Las doncellas de dote del Hospital de las Cinco Llagas de Sevilla: una lectura en clave de género. Editorial Académica Española, Berlín. - Rivasplata Varilllas, P. E. (2012) Aproximación histórica de la enfermería femenina en Europa y América. La enfermería en el hospital de las Cinco Llagas de Sevilla y los hospitales de Lima en el XVIII y parte del XIX. Editorial Académica Española, Berlín.

- Rivera Carretas, M. M. (2006) Las beguinas y beatas, las trovadoras y las cataras: el sentido libre de ser mujer. En: Historia de las mujeres en España y América Latina de la prehistoria a la Edad Media. Ediciones Cátedra, Madrid, Tomo I: 745-767.

- Salmón y Cabré M. (1998): Fascinating Women: the evil eye in Medical Scholasticism. En: Medicine form the black death to the French disease. Ashgate, Aldershot: 53-84.

- Segura Graiño, C. (2004) Mujeres, trabajo y familia en las sociedades preindustriales. En La historia de las mujeres: una revisión historiográfica. Universidad de Valladolid, Fundación española de investigación histórica de las mujeres, Valladolid : 229-248.

- Segura Graiño, C. (2001) La tela de Penélope. El tiempo para las mujeres en la Edad Media. En Rev. Arenal. 8.1: 39-54.

- Teresa Morales, C. y García Berrocal, F.J. (2013) HôtelDieu de París; orígenes y aparición de las primeras enfermeras religiosas de la historia. Rev. Cultura de los Cuidados, 17 (35): 42-54.

- Teresa Morales, C. y García Berrocal, FJ. (2013) HôtelDieu de París; reformas materiales, estructurales y funcionales entre los siglos XII y XVIII. Rev. Cultura de los Cuidados, 17(36):29-43.

- Tey i Freixa, (1996) Una aproximación a la enfermería medieval: el hospital d. en Colom en el año 1375. En: I congreso Nacional de Historia de la Enfermería. Libro de ponencias y comunicaciones. Fundación Uriach 1838, Barcelona: 32-37.

- Valdivieso Val, M. I., Tomás Pérez, M et al (2004) La Historia de las mujeres: Una Revisión Historiográfica. Universidad de Valladolid, Valladolid.

- Vinyoles Vidal, T. (2011) Hilar, cocinar, cuidar, cultivar, curara, educar, amara... quehaceres de las mujeres medievales. En: trabajo, creación y mentalidades de las mujeres a través de la historia. Una visión interdisciplinar. Universidad de Valladolid, Valladolid: 81-93. 